\title{
Serumfette und Serumeiweißkörper unter Langzeitverabreichung eines Netzmittels $\left.{ }^{1}\right)$
}

\author{
Von \\ F. Scheiffarth, H. Götz, H. SchöN †, G. Berg und W. Schulze \\ Aus der Medizinischen Universitätsklinik Erlangen-Nürnberg (Direktor: Prof. Dr. N. Henning)
}

(Der Schriftleitung zugegangen am 26. Novenber 1963)

\begin{abstract}
In tierexperimentellen Untersuchungen an Kaninchen wurde unter wöchentlich zweimaliger Applikation eines Netzmittels über insgesamt 24 Wochen das Verhalten der Serumlipide, der Serumeiweißkörper, einschließlich der Lipo- und Glykoproteide, das Verhalten der Serumlabilitätsteste und des Rest-Stickstoffes im Blut sowie schließlich nach Abschluß der Beobachtungszeit das Biopsiematerial verschiedener Organe geprüft und untersucht. Prinzipiell war dabei festzustellen, daß unter dem Einfluß von Netzmitteln, offenbar auf dem Boden einer Permeabilitätsstörung der Zellgrenzflächen, eine deutliche Hyperlipämie mit Einschwemmung nicht nur von Lipiden aus dem Protoplasma, sondern auch von kohlenhydrathaltigen Proteiden in die Blutbahn verursacht wird. Der Lipid- sowie der Kohlenhydratanteil der jeweiligen Trägetfraktionen der Serumproteine war dabei in Relation zur Proteinkomponente in unverhältnismäßig höherem Maße nachweisbar. Die erzeugte Hyperlipämie, die sich im Verlaufe des Versuches durch einen kontinuierlichen Anstieg der Serumlipide mit relativem Cholesterinester-Abfall auszeichnete, führte unter den gegebenen Versuchsbedingungen zu keinen tiefgreifenden Läsionen an den verschiedenen untersuchten Organen.
\end{abstract}

\begin{abstract}
A wetting agent was administered to rabbits twice weekly for a period of 24 weeks. The lipids, proteins, lipoproteins and glycoproteins in the serum were followed. The behaviour of the serum lability test and the residual nitrogen in the blood were studied and, at the end of the experimental period, the biopsy material from various organs was tested and investigated. The principle finding was that, under the influence of wetting agents, apparently through a disturbance of permeability at the cell surfaces, there is a marked hyperlipaemia in the blood stream, involving not only lipids from the protoplasm, but also carbohydrate-containing proteins. In each carrier fraction of the serum proteins, the lipid and carbohydrate components were found in disproportionate excess of the protein component. Under the given experimental conditions, the hyperlipaemia, which was distinguished during the experiment by a continual increase of serum lipids with a relative fall in cholesterol esters, resulted in no deep seated lesions in the different organs investigated.
\end{abstract}

Netzmittel vom Typ eines polymeren p-Isooktylpolyoxyäthylens ("Triton") erzeugen bekanntlich bereits nach einmaliger Applikation einer genügend hohen Dosis eine über Tage anhaltende Hyperlipämie (1-15). Diese unterscheidet sich von der, die man bei Cholesterinfütterung, Hypothyreodismus, essentieller Xanthomatose oder Nephrose (Lipoidnephrose) findet, dadurch, $\mathrm{da} ß$ an ihr alle Komponenten des Serumfettes (Neutralfett, Cholesterin und Phosphatide) beteiligt sind. Die Tatsache, daß diese Hyperlipämie nach einmaliger Applikation von Triton über 5 bis 15 Tage fortbestehen kann, legt die Annahme nahe, daß das Netzmittel längere Zeit unverändert im Organismus verweilt, $\mathrm{da} \beta$ also $\mathrm{der}$ Körper offenbar derartige Substanzen nicht ohne weiteres abzubauen vermag. Untersuchungen an künstlich erzeugter Hyperlipämie hatten bislang zum Ziel, Trans-. port und weiteres Schicksal der in das Blut eingeschleusten Fettsubstanzen zu studieren, wọei insbesondere die Ablagerung solcher Lipide in verschiedenen Organen interessierte $(1,9)$. Wie bereits aus grundlegenden Studien hervorgeht (12), konnte, unter Berücksichtigung des zeitlichen Ablaufes der Fettverteilung, ein Anstieg des Gesamtfettgehaltes bereits 8 Stunden nach

1) „Triton“.
Verabreichung von Triton festgestellt werden, wobei zunächst vorwiegend die Neutralfette, nach 24 bis 32 Stunden Cholesterin und Phosphatide im Serum angereichert gefunden wurden. In der abklingenden Phase sank zunächst der Neutralfettgehalt und dann erst der Gehalt an Cholesterin und Phosphatiden.

$\mathrm{Da}$ die meisten Arbeiten über den Wirkungsmechanismus von Netzmitteln mehr oder weniger kurz fristige Verlaufsuntersuchungen beinhalten, sollte in vorliegenden Studien geprüft werden, inwieweit eine langdauernde Hyperlipämie zu manifesten Serumfettveränderungen und vor allem zu Dauerschädigungen insbesondere an Leber, Niere und Gefäßapparat führen kann.

\section{Methodik}

Die Versuchsanordnung wurde so gewählt, daß unter einer relativ milde dosierten Dauerapplikation eines Netzmittels einerseits eine ausreichende Hyperlipämie und Fetteinlagerung im Gewebe, andererseits jedoch keine direkt-toxische Wirkung durch das injizierte Präparat zu erwarten war. Als Maßstab etwa aufgetretener Organfunktionsstörungen wurden die Serumlabilitätsteste, der Rest- $N$-Wert sowie die Serumelektrophorese gewählt, darüber hinaus das periphere Blutbild untersucht mit der Frage nach auftretenden Anämien oder. Leukozytosen, die u. U. ebenfalls als Ausdruck einer tiefergreifenden Organschädigung aufgefaßt werden können. 


\section{Tierexperimentelle Versucbsanordnumg}

Es wurden 5 Kaninchen mit einem durchschnittlichen Gewicht von $3-4 \mathrm{~kg}$ in Versuch genommen. Vor Versuchsbeginn wurden bei jedem Tier Ausgangswerte (A) für die verschiedenen Serumund Blutuntersuchungen festgestellt. Die Tiere wurden cholesterinfrci crnährt. Die Applikation des Netzmittels exfolgte $2 \mathrm{mal}$ wöchentlich in Form einer intravenösen Injektion von $0,5 \mathrm{ml}$ einer 50-proz. Tritonlösung pro Injektion und Tier, dies insgesamt über 24 Wochen. Kontrolluntersuchungen (K) wurden in 4wöchentlichen Abständen vorgenommen (Abb. 1).

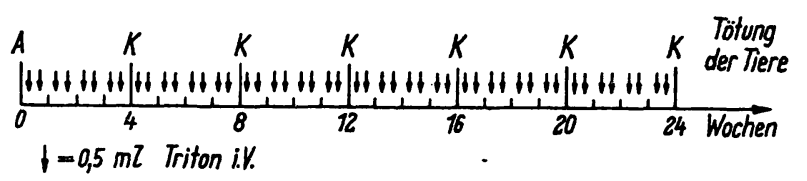

Abb. 1

Zcitplan mit Eintragung der Zeitpunkte für Ausgangswerte, Kontrollen sowie det Applikation des Netzmittels

\section{Untersucbungsmetboden}

Folgende Untersuchungsmethoden kamen zur Anwendung:

1. Gesamtfett-Bestimmung im Serum (16)

2. Cholesterin-Bestimmung im Serum (16): Gesamtcholesterin, freies Cholesterin, Cholesterinester

3. Bestimmung der Serum-Phosphatide (16)

4. Gesamteiweiß-Bestimmung im Serum mit der Biuretmethode nach WeIchSELbaum

5. Papierelektrophorese nach Grassmann und Hannig mit Protein-, Lipoproteì- sowie Kohlenhydratfärbungen (16)

6. Rest-N-Bestimmung im Serum nach KJELDAHL

7. Serumlabilitätsteste (Takata-Ara-Reaktion sowie ThymolTrübungstest)

8. Peripheres Blutbild mit Zählung der Erythrozyten und Leukozyten sowie Blutausstrich mit kombinierter MAY-GRüNwaLD Giemsa-Färbung

9. Darstellung der Organschnitte mittels Hämatoxylin-EosinFärbung nach HaIdenHaIN sowie Sudan-Fettfärbung ${ }^{1}$ ).

\section{Ergebnisse}

\section{Verbalten der Serumlipide}

Die bei unbehandelten Kaninchen gefundenen Lipidwerte im Serum bewegen sich in folgenden Grenzen (Werte in $\mathrm{mg} \%$, ohne Berücksichtigung statistischer Gesichtspunkte):

Gesamtfett

Gesamtcholesterin

Cholesterinester

freies Cholesterin

Cholesterinester in \% des

Gesamtcholesterins

Phosphatide

$$
\begin{aligned}
& 394-799(M=586 \mathrm{mg} \%) \\
& 86-142(\mathrm{M}=115 \mathrm{mg} \%) \\
& 62-91(\mathrm{M}=67 \mathrm{mg} \%) \\
& 22-51(\mathrm{M}=37 \mathrm{mg} \%) \\
& 63 \%-74 \%(\mathrm{M}=68 \%) \\
& 113-170(\mathrm{M}=145 \mathrm{mg} \%)
\end{aligned}
$$

Bereits bei erster Kontrolle ließ sich bei allen Tieren ein deutlicher Anstieg der Serumlipide mit Ausnahme der Cholesterinester aufzeigen (Tab. 1, Abb. 2 und 3). Der Cholesterinestergehalt, ausgedrückt in $\%$, nahm ab. In den weiteren Kontrollen bis zum Abschluß der Versuchsserie konnte ein kontinuierlicher Anstieg des Gesamtfett-, Gesamtcholesterin-, des freien Cholesterin- und des Phosphatid-Gehaltes verfolgt werden, während die Cholesterinester prozentual sukzessive ab-

1) Die histologischen Schnitte und deren Beurteilung verdanken wir Herrn Prof. Dr. Elster (Pathol. Institut der Univ. ExlangenNürnberg, Direktor: Prof. Dr. E. MürLER).

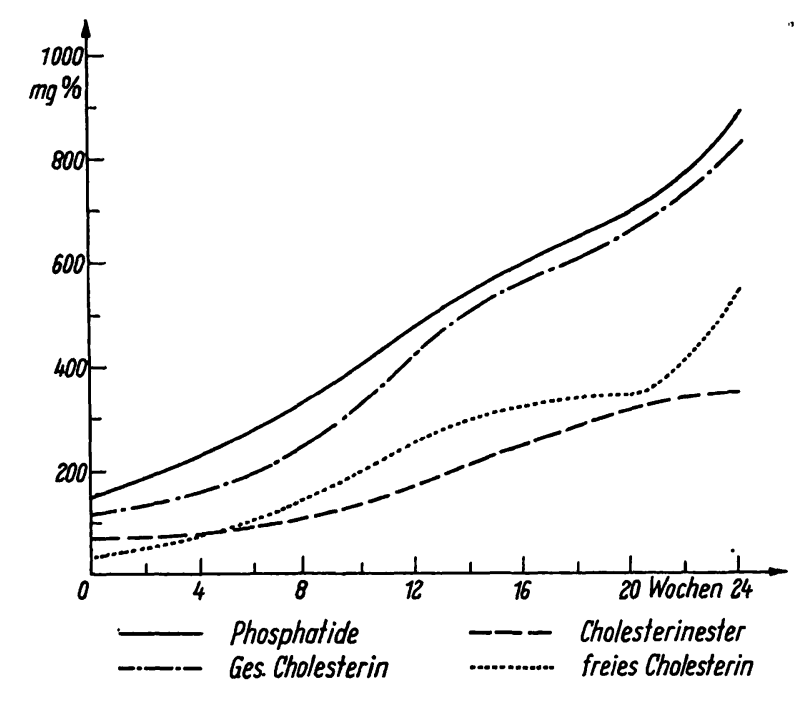

Abb. 2

Verhalten der Serumlipide nach Applikation eines Netzmittels im Dauerversuch an Kaninchen

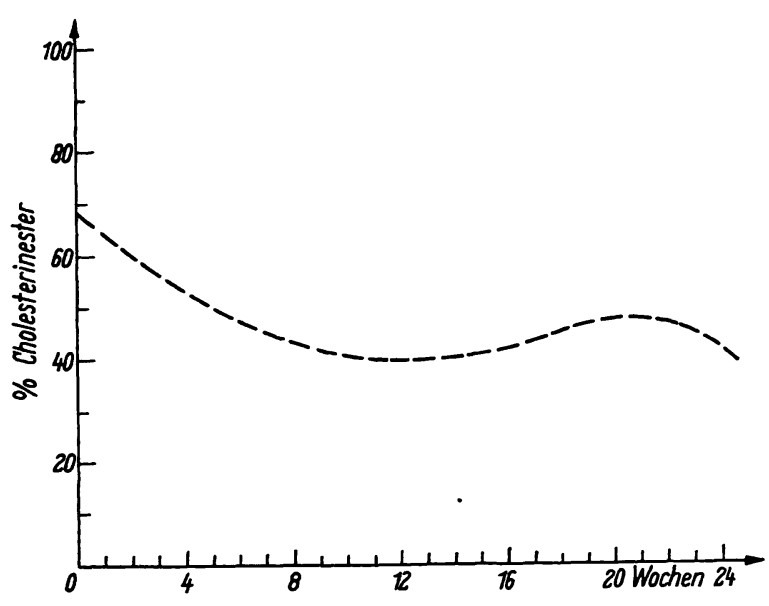

Abb. 3

Cholesterinester in \% des Gesamtcholesterins während der Dauerapplikation eines Netzmittels im Kaninchenversuch

sanken. Die Cholesterinester zeigten zwar während des Versuches ebenfalls eine Zunahme, bezogen auf das Gesamtcholesterin in \%, konnte jedoch nur ein kontinuierlicher Abfall festgestellt werden.

\section{Verbalten des Gesamteinveißes und der Serumproteine}

Das Gesamteiveiß im Serum der unbehandelten Kaninchen lag $z$ wischen $5,0 \mathrm{~g} \%$ und 7,2 $\mathrm{g} \%$ ( $M=6,1 \mathrm{~g} \%$ ). Im Verlaufe des Versuches kam es allenfalls zu einem geringen Anstieg des Gesamteiweißgehaltes im Serum der behandelten Tiere. Vergleicht man jedoch die Einzelwerte vor Versuchsbeginn und nach Abschluß der Beobachtungszeit, so finden sich unter Berücksichtigung der Streubreite keine nennenswerten Unterschiede.

Das Verhalten der Serumproteine zeigt die Abbildung 4. Bei Proteinfärbung der elektrophoretisch getrennten Serumeiweißkörper fiel im Verlaufe des Versuches eine geringe, jedoch kontinuierliche Zunahme der $\beta$-Globuline auf. - Bei Lipoidfärbung wurde nach anfänglicher starker Anreicherung der Lipid-Komponenten (bei erster Kontrolle z. B.) in den weiteren Kontrollen ein 

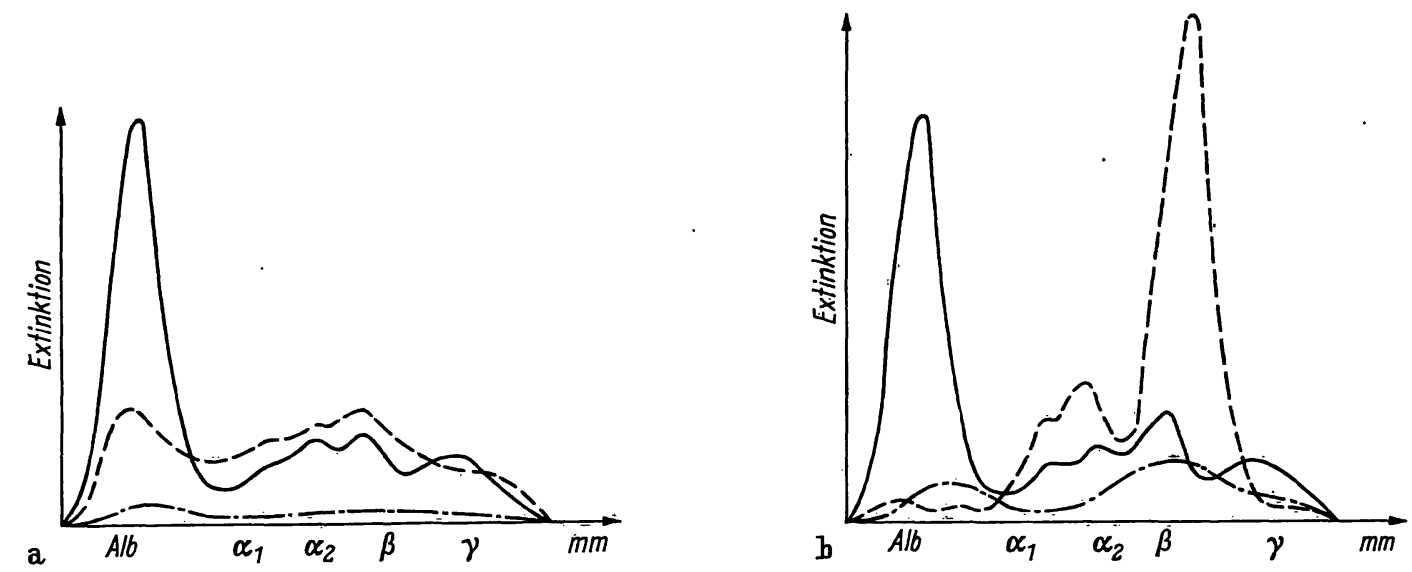

\section{Proteine $\quad---$ Glykoproteide}

Abb. 4

Darstellung der Elektropherogramme nach Protein-, Lipoid- sowie Kohlenhydratfärbung

Tab. 1

Verhalten der Serumlipide unter Dauerapplikation eines Netzmittels im Kaninchenversuch; A. = Ausgangswerte

\begin{tabular}{|c|c|c|c|c|c|c|c|}
\hline $\begin{array}{l}\text { Tier } \\
\text { Nr. }\end{array}$ & $\begin{array}{c}\text { Zeit } \\
\text { in } \\
\text { Wochen }\end{array}$ & $\begin{array}{c}\text { Gesamt-Fett } \\
\mathrm{mg} \%\end{array}$ & $\begin{array}{l}\text { Freies } \\
\mathrm{mg} \%\end{array}$ & $\begin{array}{c}\text { Cholesterin } \\
\text { Ester } \\
\mathrm{mg} \%\end{array}$ & $\begin{array}{l}\text { Ges. } \\
\text { mg\% }\end{array}$ & $\begin{array}{c}\text { Chol. Ester } \\
\%\end{array}$ & $\begin{array}{c}\text { Phosphatide } \\
\text { mg\% }\end{array}$ \\
\hline \multirow[t]{7}{*}{1} & A. & 708,0 & 27,0 & 71,0 & 98,0 & 74 & 138,0 \\
\hline & 4 & 1230,0 & 84,0 & 74,0 & 158,0 & 47 & 260,0 \\
\hline & 8 & 4100,0 & 114,0 & 98,0 & 212,0 & 46 & 395,0 \\
\hline & 12 & 6208,0 & 270,0 & 166,0 & 436,0 & 38 & 480,0 \\
\hline & 16 & 7650,0 & 385,0 & 217,0 & 602,0 & 36 & 648,0 \\
\hline & 20 & 8910,0 & 407,0 & 398,0 & 805,0 & 49 & 885,0 \\
\hline & 24 & 10660,0 & 489,0 & 403,0 & 892,0 & 45 & 999,0 \\
\hline \multirow[t]{7}{*}{2} & A. & 539,0 & 34,0 & 78,0 & 112,0 & 65 & 151,0 \\
\hline & 4 & 665,0 & 66,0 & 79,0 & 145,0 & 54 & 187,0 \\
\hline & 8 & 768,0 & 88,0 & 86,0 & 174,0 & 49 & 218,0 \\
\hline & 12 & 2870,0 & 230,0 & 148,0 & 378,0 & 39 & 440,0 \\
\hline & 16 & 7560,0 & 351,0 & $\therefore 196,0$ & 547,0 & 36 & 596,0 \\
\hline & 20 & 9244,0 & 317,0 & 275,0 & 592,0 & 47 & 638,0 \\
\hline & 24 & 14190,0 & 408,0 & 312,0 & 720,0 & 43 & 727,0 \\
\hline \multirow[t]{7}{*}{3} & A. & 799,0 & 51,0 & 86,0 & 137,0 & 63 & 170,0 \\
\hline & 4 & 1442,0 & 87,0 & 89,0 & 176,0 & 50 & 260,0 \\
\hline & 8 & 2950,0 & 257,0 & 146,0 & 403,0 & 36 & 544,0 \\
\hline & 12 & 3412,0 & 359,0 & 238,0 & 597,0 & 40 & 688,0 \\
\hline & 16 & 4518,0 & 366,0 & 346,0 & 712,0 & 49 & 814,0 \\
\hline & 20 & 5636,0 & 421,0 & 388,0 & 809,0 & 48 & 926,0 \\
\hline & 24 & 6862,0 & 682,0 & 416,0 & 1098,0 & 38 & 1112,0 \\
\hline \multirow[t]{7}{*}{4} & A. & 394,0 & 22,0 & 62,0 & 86,0 & 72 & 113,0 \\
\hline & 4 & 748,0 & 35,0 & 63,0 & 98,0 & 64 & 147,0 \\
\hline & 8 & 1250,0 & 102,0 & 86,0 & 188,0 & 46 & 240,0 \\
\hline & 12 & 2786,0 & 265,0 & 147,0 & 412,0 & 36 & 455,0 \\
\hline & 16 & 2915,0 & 264,0 & 212,0 & 476,0 & 44 & 488,0 \\
\hline & 20 & 3020,0 & 271,0 & 246,0 & 517,0 & 48 & 636,0 \\
\hline & 24 & 3620,0 & 778,0 & 306,0 & 784,0 & 39 & 795,0 \\
\hline \multirow[t]{7}{*}{5} & A. & 490,0 & 51,0 & 91,0 & 142,0 & 64 & 165,0 \\
\hline & 4 & 730,0 & 103,0 & 95,0 & 198,0 & 48 & 287,0 \\
\hline & 8 & 1212,0 & 177,0 & 109,0 & 286,0 & 38 & 292,0 \\
\hline & 12 & 2358,0 & 174,0 & 134,0 & 308,0 & 44 & 310,0 \\
\hline & 16 & 4386,0 & 247,0 & 213,0 & 460,0 & 46 & 468,0 \\
\hline & 20 & 5006,0 & 286,0 & 256,0 & 542,0 & 47 & 698,0 \\
\hline & 24 & 5800,0 & 394,0 & 302,0 & 696,0 & 43 & $814,0 \ldots$ \\
\hline
\end{tabular}


nur geringer Anstieg der Lipoproteide in den Kaninchenseren gefunden. Bei Kohlenhydratfärbung fiel, insbesondere bei letzter Kontrolle, eine enorme Anreicherung von Glykoproteiden im Bereich der $\beta$ - (evtl. sogar $\beta(\gamma$-?)-Zone auf. Auch die Glykoproteide des $\alpha_{1}$ - und $\alpha_{2}$-Systems sind relativ vermehrt, während die schnell wandernde Glykoproteidgruppe (AlbuminBereich), die vor Behandlung der Tiere relativ stark vertreten war, eher vermindert ist.

\section{Verbalten der Serumlabilitätsteste und des Rest- $N$ im Serum}

Die Serumlabilitätsteste zeigten während und auch am Ende der Beobachtungszeit bei keinem der Versuchstiere nennenswerte Abweichungen vom Normalen. Desgleichen verhielten sich die Rest-N-Werte bei allen Kontrollen und Tieren in physiologischen Grenzen.

\section{Verbalten des peripheren Blutbildes}

Die Komposition der Blutelemente bei unbehandelten Tieren entsprach der für Kaninchen bekannten Verteilung, d. h. es ergab sich eine Erythrozytenzahl zwischen 4,2 und 5,8 Mill. $/ \mu \mathrm{l}(\mathrm{M}=4,9 \mathrm{Mill} . / \mu \mathrm{l})$, eine Leukozytenzahl zwischen 4600 und $8500 / \mu \mathrm{l} \quad(\mathrm{M}=$ $6300 / \mu \mathrm{l})$ und im Differentialausstrich die Auffälligkeit eines umgekehrten Verhältnisses der Neutrophilen zu Lymphozyten (1:4), wie wir es vom Menschen her nicht gewohnt sind. Im Verlaufe des Versuches konnte bei allen Tieren eine deutliche Leukozytose mit Werten zwischen 13000 und $19300(\mathrm{M}=15$ 120)/ $\mathrm{\mu l}$ am Ende der Beobachtungszeit festgestellt werden. Im Differentialausstrich waren dagegen keine Besonderheiten aufgefallen. $\mathrm{Zu}$ erwähnen ist aus den letzten beiden Kontrollen die außerordentliche Neigung der Erythrozyten zu Konglomerat- und Geldrollenbildung.

\section{Beobacbtungen bei den Blutentnabmen und am Verbalten der Tiere}

Blutentnahmen, die unmittelbar nach Triton-Injektion vorgenommen wurden, zeigten eine deutliche Hämolyse des Serums. Es wurde infolgedessen darauf geachtet, daß die Blutentnahmen frühestens 24 Stunden nach vorangegangener Triton-Injektion vorgenommen wurden. Das Serum der Versuchstiere war außerdem bereits bei erster Kontrolle und von da an bis Abschluß der Versuchsreihe deutlich lipämisch. - Der Kräftezustand der Kaninchen war über die gesamte Beobachtungszeit als durchaus gut zu bezeichnen, was im übrigen auch im Verhalten des Gewichtes der Tiere zum Ausdruck kam. Erst in der zweiten Hälfte des Versuchs wurden vereinzelt flüchtige Oedembildungen im Bereich des Kopfes und auch der Pfoten sowie Kratzeffekte beobachtet, die sich jedoch wieder zurückbildeten.

\section{$V$ eränderungen am Autopsiematerial}

Makroskopisch fand sich bei allen Tieren eine mehr oder weniger vergrößerte, weiche Leber, die eine relativ helle Farbe aufwies. Mikroskopisch zeigte sich das Bild einer trüben Schwellung, abwechselnd mit vakuolisierten Epithelzellen. In den periportalen Feldern fanden sich
Zellen, die mit einem feinkörnigen, gelbbraünen Pigment beladen waren. - An den Lungen war eine Einlagerung von Fett-Tröpfchen im Gefäßsystem der Alveolarsepten auffällig. - Auch im Herzmuskelsystem fanden sich vereinzelt Fett-Tröpfchen. - In der Niere zeigte sich, wie in der Leber, das typische Bild der trüben Schwellung, d.h. wolkige Auflockerung der Tubulusepithelien mit vereinzelter Vakuolenbildung und sternförmiger Einengung des Tubulus-Lumens. Die Milz war makroskopisch bei allen Tieren leicht vergrößert. Mikroskopisch fand man Retikulumzellen, die Hämosiderinkörnchen enthielten. - An Darm, Nebennieren und quergestreifter Muskulatur waren morphologisch keine Veränderungen faßbar.

\section{Diskussion}

Die vorliegenden Untersuchungsergebnisse mit einem über 24 Wochen regelmäßig applizierten, hochwirksamen Netzmittel im Kaninchen-Tierversuch sollen die Wirkungsweise bzw. die Folgen einer Dauerlipämie veranschaulichen. - Wie zu erwarten, kam es bereits nach erster Injektion und von da an über die gesamte Beobachtungszeit zu einer Hyperlipämie, die durch einen kontinuierlichen Anstieg des Gesamtfettes, des freien und des Gesamtcholesterins sowie der Phosphatide bedingt und, wenigstens in den ersten Kontrollen, durch eine Vermehrung der im $\beta$-Globulin-Bereich wandernden Serumlipide - und zwar sowohl des Proteinanteils als auch der an diese Fraktion gebundenen Fettkomponenten - ausgezeichnet war. Auf Grund der Lipoidelektrophorese ist der Fettanteil weitaus größer als die Zunahme des Trägerproteins, d. h. es besteht wahrscheinlich bei dieser Trägerfraktion eine außerordentlich hohe Bindungskapazität für Fette. - Während unter einer fortlaufenden Applikation des Netzmittels die Serumlipide insgesamt anstiegen, fand sich, bezogen auf das Gesamtcholesterin, ein kontinuierlicher Cholesterinestersturz, was im übrigen auch KeLLNER $(9 a, b)$, der mit derselben Tierspezies arbeitete, beobachtet hat.

Eine klare Vorstellung über die Freisetzung von Lipiden unter dem Einfluß von hochaktiven Netzmitteln besteht heute, trotz mehrfacher Studien unter verschiedenen Gesichtspunkten und Versuchsanordnungen, noch nicht. Es sei in diesem Zusammenhang auf die einschlägige Literatur verwiesen $(1,5-9,11-14,17-19)$ und, $z u-$ sammenfassend, zu diesem Problem folgendes erwähnt: Netzmittel scheinen in erster Linie die Zellpermeabilität um ein Vielfaches zu erhöhen, wodurch offenbar zelleigene Lipide liberiert und in die Blutbahn abtransportiert werden; das gilt in besonderem Maße für die fettspeichernden Zellen und Organe. Für diese Hypothese spricht u. a. die Tatsache, daß im Tierexperiment neben Lipiden u. a. auch Proteine, insbesondere Glykoproteide im Blutstrom vermehrt angetroffen werden, was ebenfalls auf eine Freisetzung solcher Proteide aus den durch das Netzmittel geschädigten Zellen zurückzuführen ist. $\mathrm{Ob}$ aliein die Hypothese einer Permeabilitätserhöhung ausreicht, um die Hyperlipämie zu erklären, ist fraglich, zumal Ausmaß und Dauer solcher Hyperlipämien, auch 
dann, wenn man die unterschiedlichen Dosen und die ebenfalls verschiedenen Beobachtungszeiten der in der Literatur mitgeteilten Angaben berücksichtigt, augenscheinlich in keinem Verhältnis zu der gesetzten ZellLäsion stehen. Die Hyperlipämie, die z. B. durch eine einmalige Applikation eines Netzmittels ausgelöst werden kann, nimmt in Stunden kontinuierlich zu, um selbst nach Tagen nicht wieder auf physiologische Werte zurückzukehren $(5,9,12)$. Es wurde aus diesem Grunde u. a. eine Aktivierung der Fettsynthese unter dem Einfluß von Netzmitteln diskutiert. Die vorliegenden Untersuchungsergebnisse lassen zu dieser Frage keine Stellungnahme $z u, d a$ in dieser Versuchsreihe stetig neue Reize gesetzt wurden.

Auf Grund des Verhaltens des Gesamteiweißes und der Serumelektrophorese (Proteinfärbung) konnten keine tiefgreifenden Änderungen der Serumproteinrelation aufgezeigt werden, wie dies von anderer Seite $(1,2,12$, 13) bei allerdings etwas unterschiedlicher Versuchsanordnung und anderer Tierspezies beobachtet wurde. Möglicherweise spielen bei jenen Befunden versuchsbedingte, gehäufte Blutentnahmen eine maßgebliche Rolle für die Entstehung einer Hypalbuminämie bzw. Dysproteinämie. Die lediglich für die $\beta$-Globuline beobachtete Zunahme von Protein bzw. Lipoproteid war $z$ war bis zu einem gewissen Grade auffällig, jedoch nicht signifikant, d. h. die Einzelwerte bewegten sich noch immer im Rahmen der für Kaninchen als normal anzusehenden Bereiche. Möglicherweise sind diese nur wenig imponierenden Serumproteinveränderungen auf die von uns gewählte relativ niedrige Dosis des Netzmittels zurückzuführen. Im Gegensatz hierzu steht die Tatsache, daß im Verlaufe der Beobachtungszeit die Glykoproteide des Serums offenbar einen tiefgreifenden Wandel erfahren haben. Es kam dabei zu einer Verschiebung in Richtung der $\beta$-Globuline. Die Anreicherung von Glykoproteiden im Serum bei Anwendung von Netzmitteln deckt sich prinzipiell mit den Befunden auch anderer Autoren $(12,13)$. Dort wird allerdings nicht sicher entschieden, ob es sich um die Anreicherung von $\beta$ - oder $\gamma$-Globulinen handelt, während auf Grund der vorliegenden Untersuchungsergebnisse einwandfrei die Glykoproteidvermehrung vorwiegend in $\operatorname{den} \beta$ Globulinbereich fällt, also jenen Proteinen zuzuordnen ist, welche zugleich als hauptsächliche Trägerfraktion für Lipide fungieren $(20,21)$. - Die Feststellung, daß in vorliegender Versuchsreihe die Serumlabilitätsteste und der Rest-N praktisch keine Änderungen zeigten, sagt aus, daß offenbar noch keine erheblichen Funktionsstörungen an Leber oder Niere vorgelegen haben.

Die Beobachtung, daß im unmittelbaren Anschlu $\beta$ an die Netzmittelinjektionen Hämolyse auftrat, entspricht den Berichten, daß schlechthin bei jeder hochgradigen Lipämie hämolytische Begleitphänomene faßbar werden (22-31). Die auch in den vorliegenden Ergebnissen festgestellten Hämosiderinablagerungen in Leber und Milz sprechen dafür, daß eine vermehrte Erythrozytenmauserung erfolgt ist. $\mathrm{Ob}$ bei den Tritonversuchen das Netzmittel als solches eine Schädigung an den Erythrozyten gesetzt haben kann, oder ob die Anreicherung von Lipiden im Serum die Hämolyse bedingt hat, kann nicht entschieden werden. Eine bleibende Anämie wurde bei den Versuchstieren nicht beobachtet. Inwieweit der zweifellos eindrucksvollen Leukozytose als Begleitsymptom eines etwa unspezifischen Entzündungsprozesses oder als Ausdruck einer allgemeinen Zellstoffwechselstörung Bedeutung zukommt, ist im Zusammenhang mit den vorliegenden Befunden schwer zu entscheiden, zumal typische Zeichen einer Entzündungsreaktion weder aus dem Differentialblutbild noch aus den Serumlabilitätsproben noch aus histopathologischen Befunden der Organe abzuleiten sind.

Die vorliegenden autoptischen Befunde der Versuchstiere entsprechen den morphologischen Ergebnissen von Keliner (9). Es handelt sich hierbei im wesentlichen um gewerbliche Veränderungen vom Typ der trüben Schwellung und somit um relativ geringfügige Veränderungen an den verschiedenen Organen. Frühere Beobachtungen an Rattenorganen (12) mit den Zeichen einer großtropfigen Organverfettung und sogar einzelnen Zellnekrosen sind wahrscheinlich auf die weitaus höheren Dosen deș Netzmittels zurückzuführen. Das in den Nierentubuli beobachtete Phänomen der trüben Schwellung mit vereinzelten Fettvakuolen kann allein auf Rückresorptionsvorgänge der von den Glomerula ausgeschiedenen Fett- und Eiweißstoffen bezogen werden und muß infolgedessen nicht Ausdruck einer etwa beginnenden primären Tubulusschädigung sein.

Gemessen an den hier vorliegenden Versuchsergebnissen scheinen in einem primär gesunden Organismus die Kompensationsprinzipien bei einem Überangebot von zirkulierenden Fetten und fettähnlichen Substanzen zur Verhütung tiefgreifender Organläsionen in hohem Maße wirksam zu sein, selbst dann, wenn eine Hyperlipämie relativ hoch und über einen relativ langen Zeitraum existent war.

\section{Literatur}

1. BंERG, G. und H. SchöN, Arzneimittel-Forsch., Aulendorf 7 , 307 (1957). - 2. Byers, S. O. und M. J. Frredman, Clin. Invest. 35, 522 (1956). - 3. Cornforth, J. W., P. D'A. HART, R. J. W. Rees und J. A. Stock, Nature 168, 150 (1951). - 4. Dubos, R. J. und G. MrddlebrooK, J. Exper. Med. 88,81 (1948). - 5. Frantz, J. D. jr. und B. T. Hinkelmann, Federat. Proc. 13, 311 (1954). - 6. Friedman, B. und S. O. Byers, J. Exper. Med. 97, 117 (1953). - 7. Gerattini, S., C. Morpurgo und N. Passerini, Experientia (Basel) 12, 347 (1956). - 8. HrRSCH, R. L. und A.
KeLlNer, J. Exper. Med. 104, 1 und 15 (1956). - 9. Kellner, A., J. W. Correll und A T. Ladd, J. Exper. Med. 93, 373 und 385 (1951). - 10. Kato, L. und B. GossY, Amer. Rev. Tbc. 75, 684 (1957). - 11. Patnode, R. A., P. C. Hudgins und B. W. JANICKr, J. Exper. Med. 107, 33 (1958). - 12. SCHÖN, H., G. BERG und M. GMÄHLICH, Arzneimittel-Forsch., Aulendorf 8, 768 (1958). - 13. Schön, H. und G. Berg, Blut 5, 297 (1959). - 14. Schotz, M. C., A. Scann und I. H. Page, Amer. J. Physiol. 188, 399 (1957). - 15. Solotorovsky, M. und F. Gregory, J. Amer. 
Rev. Tbe. 65, 718 (1952). - 16. Henning, N., Klinische Laboratoriumsdiagnostik, S. 11, 16, 21, 67, 81, 84, 85, 144 und 409. Urban \& Schwarzenberg, München und Berlin (1960). - 17. Frenci, J. E. und B. J. Morris, Physiology 138, 326 (1957). 18. Sherber, D. A. und M. M. Levites, J. A. M. A. 152, 682 (1953). - 19. Zilversmit, D. B., C. Entenmann und I. L. CihatKorr, J. biol. Chemistry 176, 209 (1948). - 20. CoHN, E. J., L.E. Strong, W. L. Hughes, D. J. Mulford, J. N. Ashworth, M. Melin und H. L. TAYlor, J. Amer. chem. Soc. 68, 459 (1946). 21. Oncley, J. L., F. R. N. Gurd und M. Melin, J. Amer. chem. Soc. 72, 458 (1950). - 22. Dunhiam, L. J. und A. Brunschwig, Arch. Surg. 48, 395 (1944). - 23. FreEMAN, L. W. und V. JohNson, Amer. J. Physiol. 124, 466 (1938). - 24. Johnson, V. und
L. W. Freeman, Amer. J. Physiol. 130, 723 (1940). - 25. LongNini, J., L. W. Freeman und V. Johinson, Federat. Proc. 1, 51 (1942). - 26. Johnson, V., J. Longnini und L. W. FreEman, Science 97, 400 (1943). - 27. Josepirs, H. W., L. E. Holt jr., H. C. Tidwell und CH. N. KadjrDr, J. Clin. Invest. 17, 532 (1938). 28. Kibbin Mac, J. M., A. Pope, S. Thayer, R. M. Ferry jr. und F. J. Stare, J. Laborat. Clin. Med. S. Louis 30, 488 (1945). 29. Kibbin Mac, J. M., J. Clin. Invest. 25, 679 (1946). - 30. Meng, H. C., Parenteral alimentation of carbohydrate and fat. Master's Thesis, Northwestern Universitiy Medical School (1946). - 31. Meng, H. C. und L. W. Freenan, J. Laborat. Clin. Med. S. Louis 33,689 (1948).

\title{
Aldosteronfraktionen im Plasma hepatektomierter Hunde')
}

\author{
Von \\ M. ManN, W. Siegenthaler, K. KRAMpf und E. ZINGG \\ Aus der Medizinischen Universitäts-Poliklinik Zürich (Direktor: Prof. R. Hegglin) und dem Experimentallabor der \\ Cbirurgischen Universitätsklinik A, Zïrich (Direktor: Prof. A. Senning)
}

(Der Schriftleitung zugegangen am 21. Februar 1964)

\begin{abstract}
Nach Injektion von 1,2- ${ }^{3} \mathrm{H}-\mathrm{d}-$ Aldosteron wurden im Plasma von 3 normalen und von 3 hepatektomierten Hunden dic prozentualen Anteile der injizierten Radioaktivität bestimmt, die als freies Aldosteron, als 3-Oxo-Konjugat und als $\beta$-Glukuronidase labile $\mathrm{pH}$ 5-Fraktion, in der das Tetrahydroaldosteronglukuronid enthalten ist, vorlagen.

Das freie Aldosteron ( $\mathrm{pH} 6$ ) ist im Plasma hepatektomierter Hunde in größerer Konzentration vorhanden als im Plasma normaler Hunde. Die pH 5-Fraktion mit dem Tetrahydroaldosteronglukuronid dagegen liegt im Plasma hepatektomierter Hunde in geringerer Konzentration vor als im Plasma normaler Hunde. Die äußerst geringe Konzentration des 3-Oxo-Konjugates sowohl im Plasma hepatektomierter als auch normaler Hunde weist bei gleichzeitigem Vorkommen erheblicher Mengen im Urin der Tiere auf eine extrem hohe renale Clearance dieses Metaboliten hin. Dies kann als Hinweis für eine möglicherweise in der Niere stattfindende Transformation von Aldosteron in das 3-Oxo-Konjugat aufgefaßt werden.
\end{abstract}

\begin{abstract}
After i. v. Injection of $1,2-{ }^{3} \mathrm{H}-\mathrm{d}-$-Aldosterone in 3 normal and 3 hepatectomised dogs the percentage of injected radioactivity of the 3 different aldosterone fractions, free aldosterone $(\mathrm{pH} 6), 3$-oxo-conjugate $\left(\mathrm{pH}_{1}\right)$ and tetrahydroaldosteroneglucuronide $\left(\mathrm{pH}_{5}\right)$ in the plasma were determined.

The free aldosterone $\left(\mathrm{pH}_{6}\right.$-fraction) in the plasma of hepatectomised dogs reaches a higher concentration than in the plasma of normal dogs. The $\mathrm{pH}_{5}$-fraction in the plasma of hepatectomised dogs has been found in a smaller amount than in non hepatectomised animals. However in the plasma of normal and hepatectomised dogs the concentration of the 3-oxo-conjugate is very small while in the urine of the same dogs a remarkable quantity of this metabolite was found. This high rate of clearance of the 3-oxo-conjugate may be considered as a suggestion for a possible transformation into this metabolite in the kidneys.
\end{abstract}

Auf Grund der im Urin von hepatektomierten Hunden nach Injektion von $1,2-{ }^{3} \mathrm{H}-\mathrm{d}$-Aldosteron gefundenen radioaktiven Aldosteronmetabolite konnten wir (1) zei= gen, daß Aldosteron bis zu einem gewissen Grade auch außerhalb der Leber metabolisiert werden kann. Dabei kann die Umwandlung von Aldosteron zum 3:OxoKonjugat weitgehend extrahepatisch stattfinden, während diejenige zum Tetrahydroaldosteronglukuronid nur

1) Diese Arbeit wurde durch die Hilfe des Schweizerischen Nationalfonds zur Förderung der wissenschaftlichen Forschung und der Stiftung für wissenschaftliche Forschung an der Universität Zürich ermöglicht. in bescheidenem Ausmaß extrahepatisch erfolgen kann. Die folgenden Ausführungen beziehen sich auf das Verhalten der verschiedenen Aldosteronfraktionen im Plasma hepatektomierter Hunde. Dabei stellte sich die Frage, ob nach Injektion von 1,2-3 $\mathrm{H}$-d-Aldosteron auch im Plasma radioaktive Aldosteronmetabolite, die somit extrahepatisch in die inaktiven Ausscheidungsformen umgewandelt würden, nachweisbar sind.

\section{Methode}

Es handelt sich um dieselbe Versuchsanordnung, die auch für den Nachweis der verschiedenen Aldosteron- 